\title{
Association for the Application of Ultrasound in Medicine and Biology of the Republic of Serbia - SECHO
}

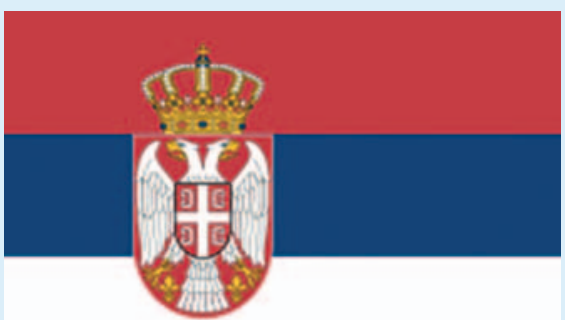

Population: 8963753 ; Area: 88361 km; Capital: Belgrade. Belgrade is the center of academical, cultural and political life in Serbia.

Dr. Danijela Miletić is the current Vice President of the SECHO Association for the Application of Ultrasound in Medicine and Biology of the Republic of Serbia. She is a gastroenterologist at the University Clinical Center of Serbia in Belgrade. Dr. Miletić's main professional work is in the field of Application Ultrasound in digestive diseaseIBD. Besides being the Vice President at SE$\mathrm{CHO}$, she is a regular member of EFSUMB, ECCO, ESGENA, and UGS.

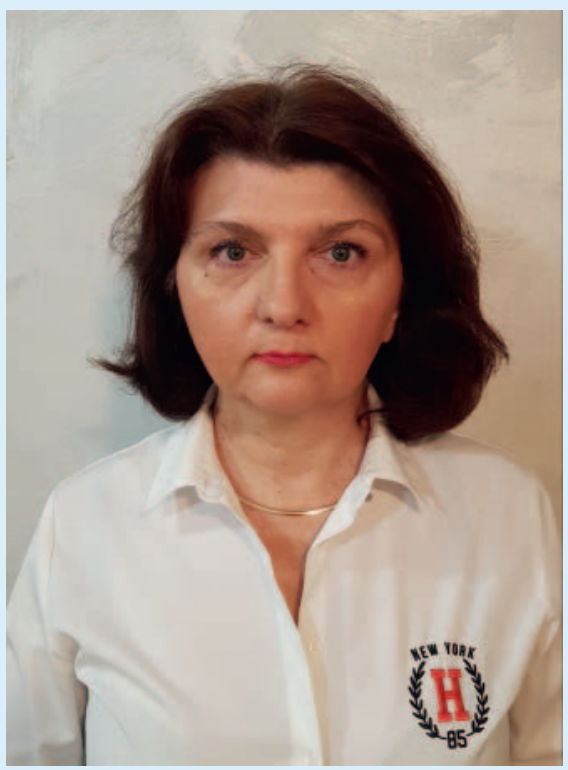

Dr. Danijela Miletić

SECHO dates its routes back to the Yugoslavian School for the Application of Ultrasound. The International School of Ultrasound was first founded by Prof. Dr. Asim

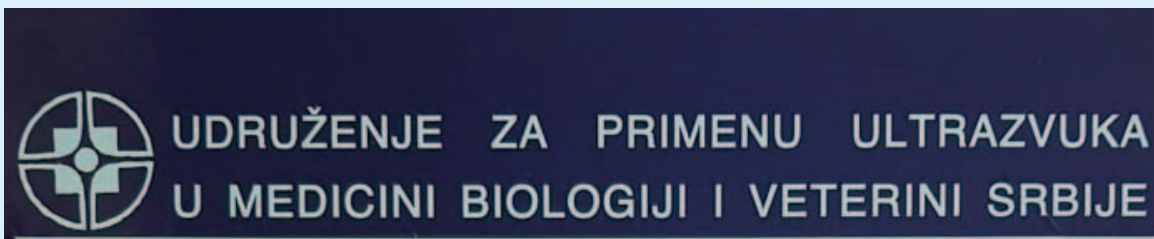

Atanasije - Tasa Marković

glavni urednik

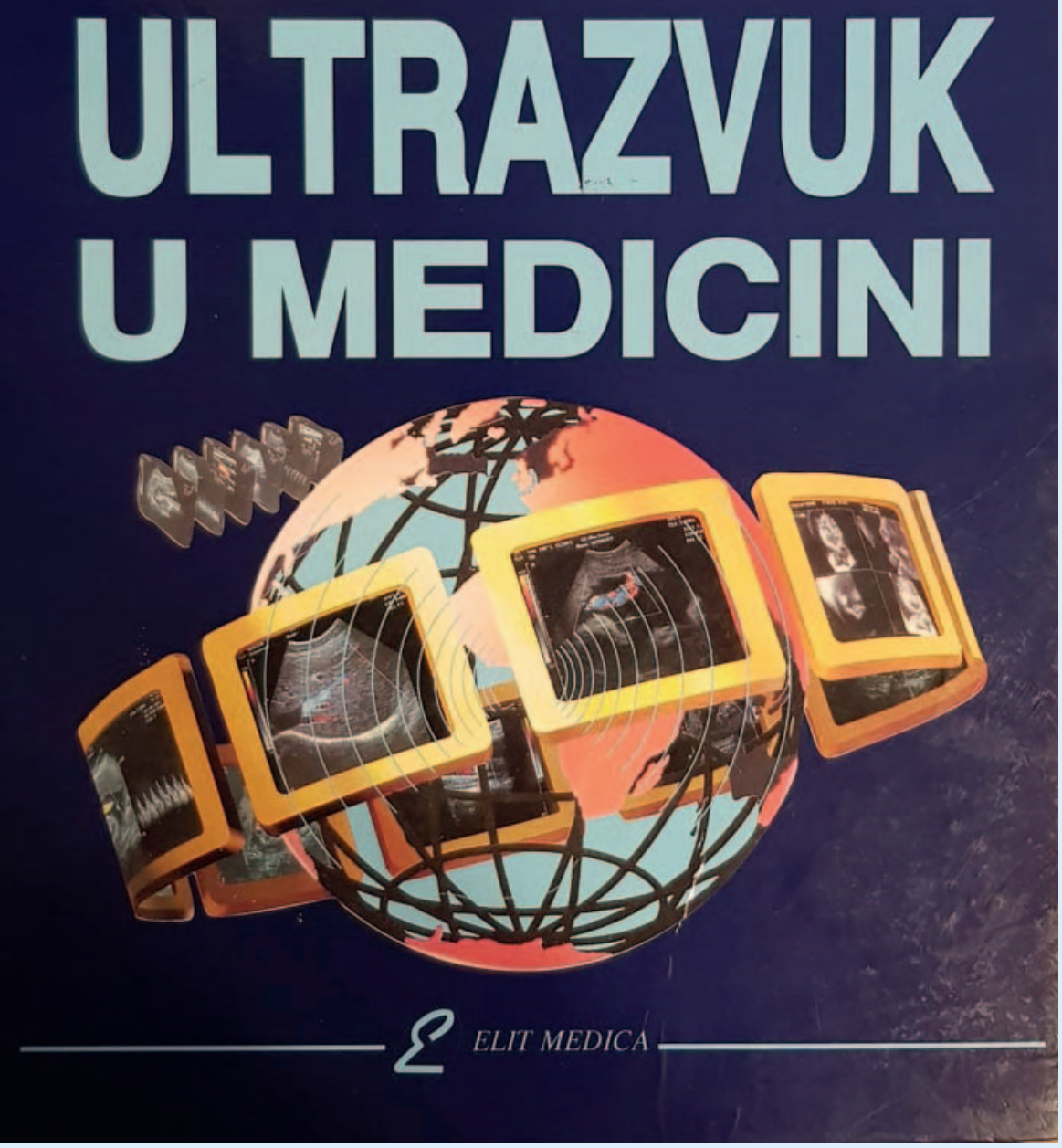

Manual written by Atanasije Tasa Marković, the headmaster of the Yugolsavian School of Ultrasound - 1997

Kurjak in Dubrovnik. Since the majority of the students and doctors were from Yugoslavia, Dr. Zoran Sretenović, decided to open another, this time a Yugoslavian School of Ultrasound in 1985.

The Yugoslavian School for the Application of Ultrasound was offering various pro- grams for all specialties and levels. It was established in Kragujevac and as the head doc. Dr Atanasije Tasa Marković was appointed.

Due to the political situation and events, the Yugoslavian School for the Application of Ultrasound was closed in early 2000. 
Nevertheless, the Yugoslavian School for the Application of Ultrasound fostered numerous professionals, who carried their work in all parts of the world and was the first of its kind.

The main communication channel currently is our Newsletter, but in the future, we are going to publish a magazine. The main focus of the magazine will be promoting the guidelines of EFSUMB, besides our practical experiences and new accomplishments in the field of Ultrasound.

\section{Training in ultrasound in Serbia}

During their medical studies, students have the opportunity to learn basic practical knowledge regarding ultrasound. Further on the if they wish to continue their education in the Application of ultrasound, there are various courses and internships at University Clinics, that are all approved fro SECHO.

\section{National Meetings in Serbia}

The national meeting is held once every two years, at the moment.

\section{Membership}

SECHO currently gathers 50 official members and 30 associates. All of our official members are part of EFSUMB as well.

\section{SECHO and EFSUMB}

Since 2020, SECHO is part of EFSUMB. We are looking forward to future cooperation. 